Volume 8, No.1.5, 2019

International Journal of Advanced Trends in Computer Science and Engineering

Available Online at http://www.warse.org/IJATCSE/static/pdf/file/ijatcse2881.52019.pdf

https://doi.org/10.30534/ijatcse/2019/2881.52019

\title{
Determination of the Pollution Free Areas Due to Chemical Release from Oil \& Gas Refinery Plant, Kerteh, Terengganu
}

\author{
Siti Musliha Binti Nor-Al-Din ${ }^{1}$, Noor Khairiah Binti Razali ${ }^{2}$, Nursyazni Binti Mohamad Sukri ${ }^{3}$, \\ Nor Najihah Binti Zainal Abidin ${ }^{4}$, Muhamad Amirul Amir Bin Mohd Daud \\ ${ }^{1}$ Universiti Teknologi MARA, Malaysia, sitim907@uitm.edu.my

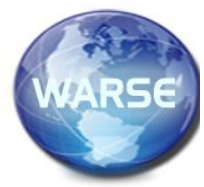 \\ ${ }^{2}$ Universiti Teknologi MARA, Malaysia, noorkhairiah@uitm.edu.my \\ ${ }^{3}$ Universiti Teknologi MARA, Malaysia, nursyazni@uitm.edu.my \\ ${ }^{4}$ Universiti Teknologi MARA, Malaysia, najihahzainal17@gmail.com \\ ${ }^{5}$ Universiti Teknologi MARA, Malaysia, ame.roll.fm@gmail.com
}

\begin{abstract}
Living near at a high-risk industry place such as oil and gas refinery plant, citizens would be inevitably exposed to the chemical releases. Thus, this study is conducted to determine the best residential area that free from the chemical release by oil and gas refinery plants. This project will be focusing on the chosen area in Kerteh, Terengganu. This is because the citizens especially the children are having health problems due to the polluted area as there are three main refinery plants located there. Hence, optimization is used to identify the chemical release free areas. Using the combination of binary integer programming and simplex method, this paper explores the selected area in finding the best location for residential and accommodations. Thus, MATLAB software is significant to use in order to solve this binary integer programming model. Finally, if it shows that the location 0 , the area that free from the chemical release is being determined.
\end{abstract}

Key words: refinery plant, pollution free areas, optimization, binary integer programming

\section{INTRODUCTION}

Kerteh Port in Terengganu is one of the four major ports in Malaysia that involves in the petrochemical industry. Kerteh Port has an incredible potential to become the National organic compound Hub Port that attributes primarily to safety procedure. However, it is inevitable that the chemical release from the refinery process will pollute the surrounding air in the immediate area where they are located and dispersed to a few distances (km) away.

Exposures to industrial air pollutants have been associated with respiratory problems and asthma symptoms in children [6]. Many health problems because of pollution are reported in several analysis studies over the past three decades. Metabolic process issues like cough and chest tightness would be the short-term effect of these pollutants exposure. While, long-term exposure to these pollutants remains largely unknown and thus, it is necessary to identify the suitable area that free from the chemical release for residential area, accommodation and others.

People choose to live in a comfortable, safe and perfect place. Related to the initiative in developing a Smart City in Malaysia, which are the main components are the infrastructure, internet of things (IOTs), environment and culture [1]. In order to provide a healthy environment place, there is a growing concern about the indoor air quality, especially in an urban area. Air pollution also contributed by the exponential growth of the vehicle population [11]. On the other side, more distress situation is particularly the air quality within the school. The school that is built close to the industrial area has been a foremost concern because of the prolonging exposure to chemical release which will cause health impact to the kids. One of the foremost industry sectors that contribute to the air pollution is the petrochemical industries. From the previous study, most of the primary school children that live near petrochemical industry has a high probability in getting respiratory symptoms due to exposure to indoor PM10 and NO2 concentration [2]. Besides that, this chemical exposure also might cause the reduction of lung function impairment to children. Furthermore, based on the context of Guidelines for Siting and Zoning of Industry and Residential Areas, it is indicating that minimum of $1 \mathrm{KM}$ or more for primary buffer distance from sensitive receptor in high risk industries, installations or activities such as petrochemical industries [5].

Oil industry releases could distress humans directly through inhalation exposure as well as indirectly through food [9]. The short-term exposure consists mainly of allergic effects, while the long-term exposure can affect respiratory system, such as asthma and an increased risk of chronic respiratory infections. Poor indoor air quality (IAQ) in school might affect the kids in their learning skill and academic 
performance [6]. Later, for a long-term it also will affect student's development as well as their future life and then to the society. Other than an indoor zone like home, they also spend most of their times in school. In this way, IAQ in school is significantly important because students spend around 5 to 7 hours in the school.

The physical condition of children is unique and more vulnerable compare to the adult; even they are the residents of the same house. Fail to prevent indoor air pollution can expose the students and staff to the long-term and short-term health problems; reduction in efficiency of teachers and worsen the student learning environment and comfort. The particulate air pollution was associated with the growth of respiratory symptoms effects, school absences and medication use for asthmatic children [10]. Thus, this will increase the difficulty in the finding of the suitable residential area that free from the air pollution in Kerteh, Terengganu. Therefore, it is very important to identify chemical release free areas and to determine the best area for housing and accommodation in Kerteh, Terengganu.

\section{METHODOLOGY}

Mathematical optimization is determination of the best element with respect to a few criterion from a few set of accessible options. This study was purposely to determine the best residential areas that are free from chemical release. The optimum result is be dependent on the main principle of this model, which is minimizing the best residential areas and maximizing the polluted areas.

Optimization model is where the variables and constrains are given in a mathematical function. Therefore, binary integer programming (BIP) and simplex method were used in this research. The BIP method used only the binary numbers that are 0 or 1 only.

The problem will be put into standard form:

- The objective function is $Z=\sum_{j=1}^{n} c_{j} x_{j}$.

- Inequalities form with the $\mathrm{m}$ constraints is $\sum a_{i j} x_{j} \leq b_{i}$ for $i=1,2, \ldots, m$

- Binary variable will be all $x_{j}$ where $j=1,2, \ldots, n$ (can only have a value of 0 or 1 ).

- All objective function coefficients are non-negative.

- Binary variables are defined as:

Let $Y=\left\{\begin{array}{l}1, \text { if the event take place } \\ 0, \text { if the event doesn' } t \text { take place }\end{array}\right.$
The simplex method is an algorithm that finds the solution of linear programming. In mathematical ways, it can show in the form $Z=C^{\top} x$ that subject to $A x \geq b$, with $x \geq 0$ where, $b \geq 0$ ,$C^{\top}$ is the coefficient, $x$ is the variable, and $b$ is the feasible solution. Variables are referring to the focal areas that had been set up, while the constraints are restricted based on the location of the refinery plants as showed in Figure 2.

This optimization model was implemented to the sample of layout that developed from the actual layout of refinery plant in Kerteh, Terengganu (Figure 1). The areas that will be focusing is in between Ethylene (M) Sdn. Bhd, PETRONAS Penapisan (Terengganu) Sdn. Bhd, and Onshore Gas Terminal (OGT). The 2-Dimesional (2D) plan layout as shown as Figure 2 is built as an optimization model to be tested and analyzed. Then, the boundary and refinery plant will be defined based on the grid in the layout (Figure 3). In justifying the actual result, the assumption used was significantly important which highlighting that the free chemical released on the nodes, will represent the same attribute for the areas around it.

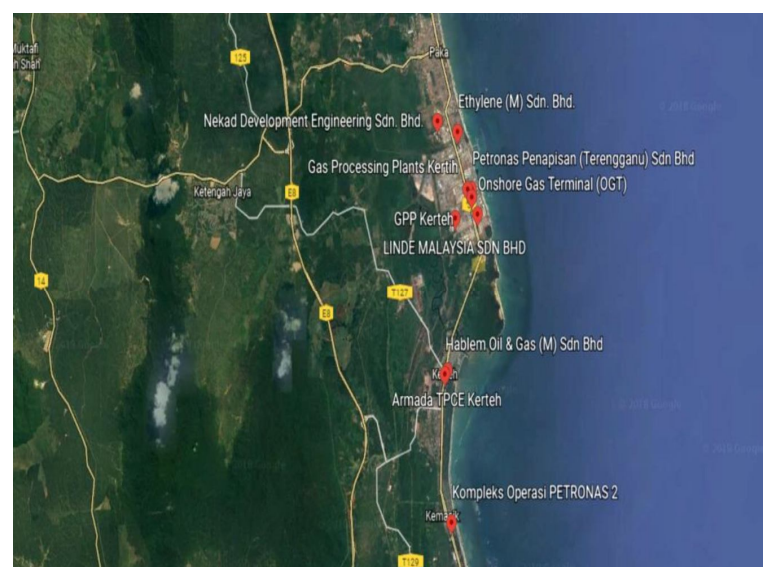

Figure 1: Sample Layout of Refinery Plant in Kerteh (Source: Google Maps)

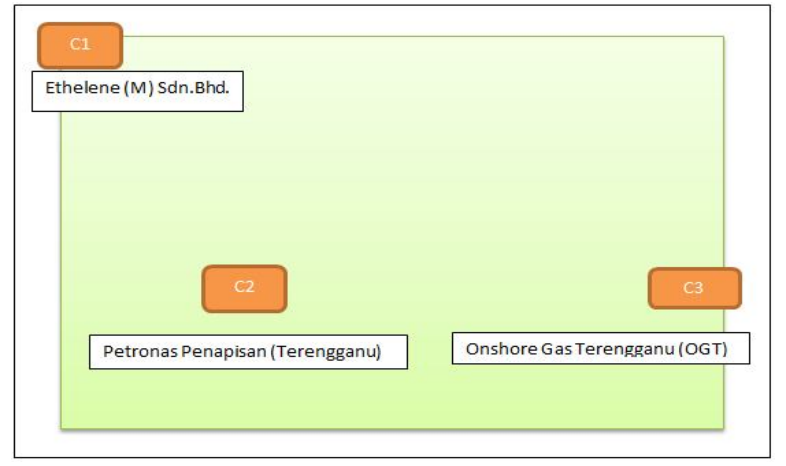

Figure 2: Sample of the two-dimensional chosen of Kerteh area layout 


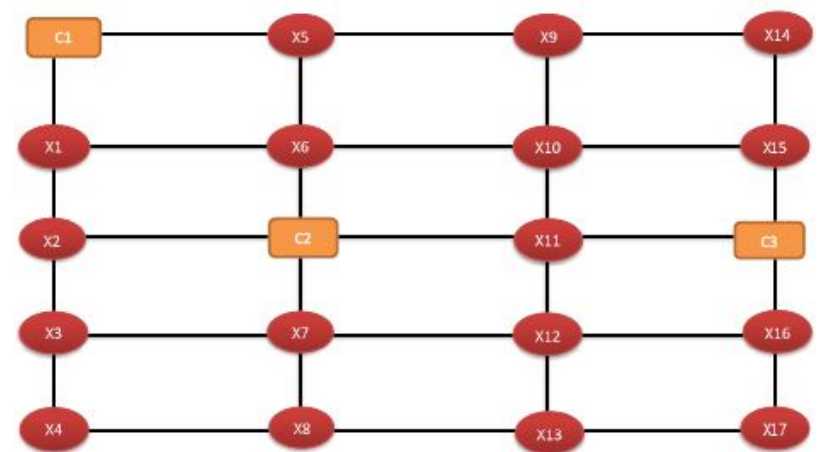

Figure 3: 12 grid cells of the 2D layout with $3 \times 17$ nodes ( 3 refinery plant nodes and 17 area nodes)

The problem is implied in matrix notation:

$$
\min C^{\top} \text {, s.t. } \quad A x \geq b \quad x \in(0,1)
$$

Let $A_{i j}=\left\{\begin{array}{l}1, \text { if the refinery plant, } \mathrm{i} \text { can affect the cell, } \mathrm{j} \\ 0, \text { otherwise }\end{array}\right.$

Let $x_{j}= \begin{cases}1, & \text { if the cell, } j \text { is affected by chemical release } \\ 0, & \text { otherwise }\end{cases}$

Therefore, matrix A will produce as below:

$\min \left(1^{\top} x\right)$, s.t.

$\left(\begin{array}{lllllllllllllllll}1 & 1 & 1 & 1 & 0 & 0 & 0 & 0 & 0 & 0 & 0 & 0 & 0 & 0 & 0 & 0 & 0 \\ 0 & 0 & 0 & 1 & 1 & 1 & 1 & 1 & 1 & 0 & 0 & 0 & 1 & 0 & 0 & 0 & 0 \\ 0 & 0 & 0 & 0 & 0 & 0 & 0 & 0 & 1 & 0 & 0 & 0 & 1 & 1 & 1 & 1 & 1\end{array}\right)$

Then, produce the optimization:

$\min \left(1^{\top} x\right)$, s.t.

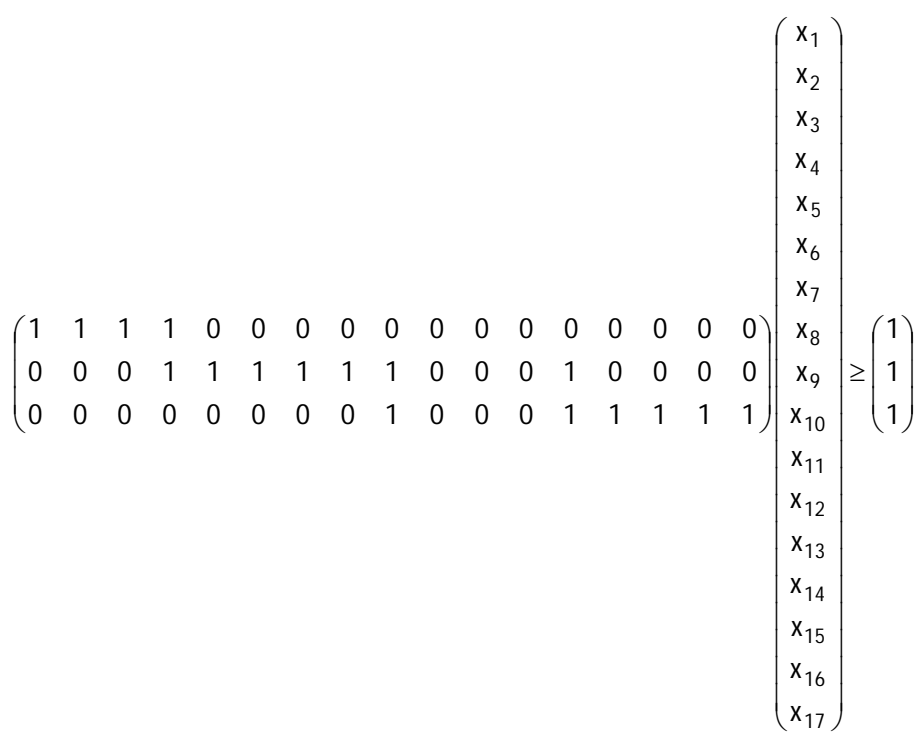

Based on the optimization model above, the result should be more accurate and realistic by making the grid size smaller. Thus, the model were extended and developed for the layout with $3 \times 32$ nodes. The feasible solution were solved using MATLAB software.

\section{RESULT}

In these results, the blue nodes that shown in Figure 4 and 5 will represent the area that had been polluted by the chemical release. For each blue node, it will cover the 4 grids. Based on these layouts, the pollution free areas will be referred to the green shaded region.

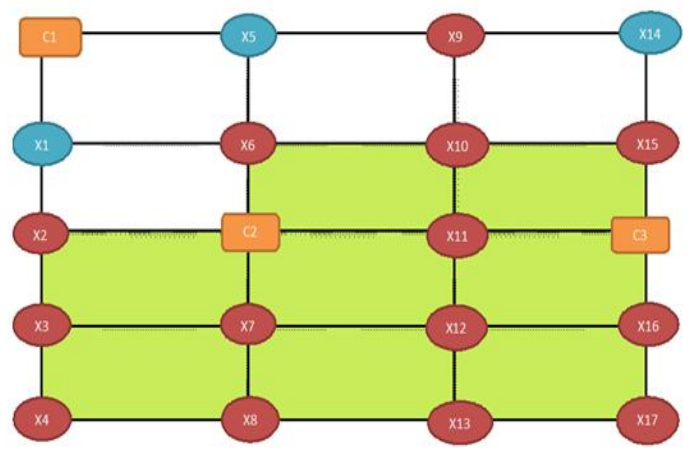

Figure 4: The shaded region of chemical release free area for $(3 \times 17)$ nodes.

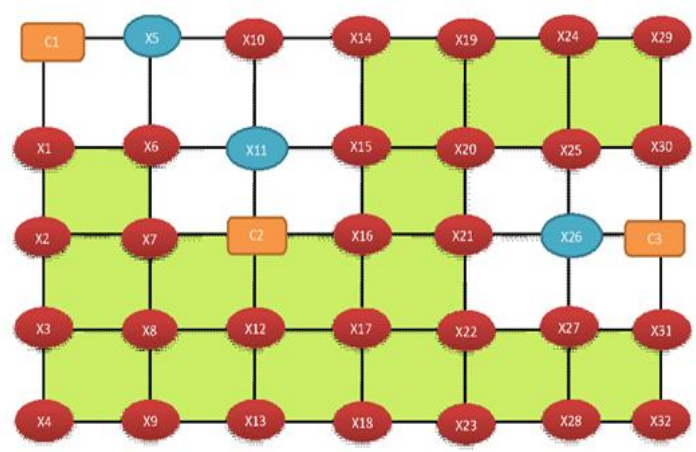

Figure 5: The shaded region of chemical release free area for $(3 \times 32)$

Percentage of non-coverage cells for each layout were calculated and presented in the Table 1 below:

Table 1: The percentage of the best residential areas

\begin{tabular}{|c|c|}
\hline Layout & $\begin{array}{c}\text { Percentage of non-coverage cells } \\
\text { (best residential areas) }\end{array}$ \\
$=\frac{\text { number of non } \text { - polluted cells }}{\text { total cells }} \times 100$ \\
\hline $1(3 \times 17$ nodes $)$ & $\frac{8}{12} \times 100=66.67 \%$ \\
\hline $2(3 \times 32$ nodes $)$ & $\frac{15}{24} \times 100=62.50 \%$ \\
\hline
\end{tabular}


By observing the above result, the $2^{\text {nd }}$ layout with $3 \times 32$ nodes produce a lower percentage compare to the $1^{\text {st }}$ layout. Using the layout with smaller grid size would produce a more reliable outcome. It is proven that by decreasing the grid size, the number of nodes will be increased. Thus, each node will represent a smaller coverage areas. That will make the result become more reliable and realistic.

\section{CONCLUSION}

The solution was formulated to this optimization problem, in order to fulfill the constraints while minimizing the number of best residential areas and fixed number of refinery plants. The algorithm works for polygonal regions and the areas to be covered as grids. This mapping allows us to illustrate the actual problem to the set coverage model and solve it using 0 -1 programming.

By applying the Binary Integer Programming and Simplex Method, we could determine the best residential areas that are free from the chemical release by oil and gas refinery plants. The study can be extended by having much smaller grid size in order to produce more reliable result which can be applied in the real field. The solution also would be formulated using a different programming language that are able to solve the bigger system.

\section{REFERENCES}

1. Athirah, N., Rosziati, I. \& Sapiee, J. Designing a Model for Smart City through Digital Transformation., International Journal of Advanced Trends in Computer Science Engineering (IJATCSE), Vol. 8, pp. 345-351, 2019.

https://doi.org/10.30534/ijatcse/2019/6281.32019

2. Ayuni, N. A., \& Juliana, J. Exposure to PM10 and NO2 and association with respiratory health among primary school children living near petrochemical industry area at Kertih, Terengganu. Journal of Medical and Bioengineering, Vol, 3(4), 2014.

https://doi.org/10.12720/jomb.3.4.282-287

3. Choo, C. P. \& Jalaludin, J. An overview of indoor air quality and its impact on respiratory health among Malaysian school-aged children, in Environmental Health, $1^{\text {st }}$ ed. vol. 30, 2015, pp. 9-18.

4. Erdem, U. M. \& Sclaroff, S. Automated camera layout to satisfy task-specific and floor plan-specific coverage requirements, Computer Vision and Image Understanding, Vol. 103, 2006, pp. 156-169.

https://doi.org/10.1016/j.cviu.2006.06.005

5. Guidelines for Siting and Zoning of Industry and Residential Areas, Department of Environment Ministry of Natural Resources and Environment Malaysia, $2^{\text {nd }}$ ed., 2012.

6. Kamaruddin, A. S., Jalaludin, J., \& Hamedon, T. Exposure to Industrial Air Pollutants and Respiratory Health School and Home Exposure among Primary School Children in Kemaman, Terengganu. International Journal of Applied Chemistry, Vol. 12(1), pp. 45-50, 2016.
7. Maryam, Z., Hazrin, A. H., Hizrri, A., Norhidayah, A., Samsuddin, N.3, Mohd Shukri, M.A. Association Of Particulate Matter (Pm) With Respiratory Symptoms Among Children In Selected Primary Schools In Pahang. Journal CleanWAS, Vol. 2 (1), pp.11-15, 2018. https://doi.org/10.26480/jcleanwas.01.2018.11.15

8. Musliha, S. Optimization of the location of camera in two dimensional floor layout, M.S. dissertation, Dept. Sc., UTM, Malaysia, 2013.

9. Opera, C. D., \& Mihul, A. C. (2003). Accumulation of specific pollutants in various media in the area affected by a petrochemical center in Romanian Reports in Physics, Vol. 55, 2003, pp. 82-90.

10. Peters A, Dockery DW, Heinrich J, Wichmann HE. Shortterm effect of particulate air pollution on respiratory morbidity in asthmatic children. Journal of European Respiratory 1997, Vol. 10, pp. 872-79, 1997.

11. Vijayan, V. P. \& Paul, B. Traffic scheduling for Green City through energy efficient Wireless sensor Networks, International Journal of Advanced Trends in Computer Science Engineering (IJATCSE), Vol. 8, pp. 1571-1575, 2019. https://doi.org/10.30534/ijatcse/2019/81842019

12. Yahaya, N., Ali, A., \& Ishak, F. (2006). Air Pollution Index (API) and the effects on human health: Case study in Terengganu City, Terengganu, Malaysia. International Association for People Environment Studies (IAPS) Conference, Alexandria, Egypt, September 2006.

13. Yang, C. Y., Wang, J. D. \& Chan, C. C. Respiratory and irritant health effects of a population living in a petrochemical-polluted area in Taiwan, in Environmental Research, Vol. 74, 1997, pp. 145-149. https://doi.org/10.1006/enrs.1997.3762 